\title{
The Epilepsy Spectrum: Targeting Future Research Challenges
}

\author{
Gregory L. Holmes ${ }^{1}$ and Jeffrey L. Noebels ${ }^{2}$ \\ ${ }^{1}$ Department of Neurological Sciences, University of Vermont College of Medicine, \\ Burlington, Vermont 05405 \\ ${ }^{2}$ Developmental Neurogenetics Laboratory, Departments of Neurology, Neuroscience, and Molecular and \\ Human Genetics, Baylor College of Medicine, Houston, Texas 77030 \\ Correspondence: gregory.holmes@uvm.edu
}

\begin{abstract}
There have been tremendous recent advances in our understanding of the biological underpinnings of epilepsy and associated comorbidities that justify its representation as a spectrum disorder. Advances in genetics, electrophysiology, and neuroimaging have greatly improved our ability to differentiate, diagnose, and treat individuals with epilepsy. However, we have made little overall progress in preventing epilepsy, and the number of patients who are cured remains small. Likewise, the comorbidities of epilepsy are often underdiagnosed or not adequately treated. In this article, we suggest a few areas in which additional research will likely pay big dividends for patients and their families.
\end{abstract}

$T^{\mathrm{h}}$ he pace of recent advances in epilepsy has been explosive, driven by our increasing understanding of the disorder's inextricable links to development, excitability, and plasticity in the central nervous system, and by the steady emergence of techniques to analyze these properties at high resolution in both human and animal models. As shown in Figure 1, there has been a near doubling in published articles dealing with epilepsy over the last 15 years. Experimental research has produced a threefold increase in peer-reviewed papers since 1970. Subareas within epilepsy research that have shown nearly exponential increases in activity include genetic models, epileptogenesis, comorbidities, and mortality.

Although it is gratifying that epilepsy is now receiving the attention it deserves based on its prevalence, the new knowledge comes at a cost; the more we learn about the complex biology of epilepsy, the further away we appear to be from the therapeutic goalposts. Despite our advances in more precisely defining seizure phenotypes, isolating causative genes, and developing specific therapies, much more work needs to be done before we can hope to prevent epilepsy in vulnerable populations, reduce comorbidities associated with epilepsy, and effectively eliminate seizures without causing adverse side effects. However, clinical heterogeneity and molecular complexity are features of all human disease, and serve to position the field of epilepsy research alongside that of cancer in allowing the opportunity to make steady inroads in curing certain forms (Noebels 2015). In the future, rather than measuring our progress by the prevalence of the disorder as a whole, we will be monitoring research progress within the many

Editors: Gregory L. Holmes and Jeffrey L. Noebels

Additional Perspectives on Epilepsy: The Biology of a Spectrum Disorder available at www.perspectivesinmedicine.org

Copyright (C) 2016 Cold Spring Harbor Laboratory Press; all rights reserved

Advanced Online Article. Cite this article as Cold Spring Harb Perspect Med doi: 10.1101/cshperspect.a028043 
G.L. Holmes and J.L. Noebels
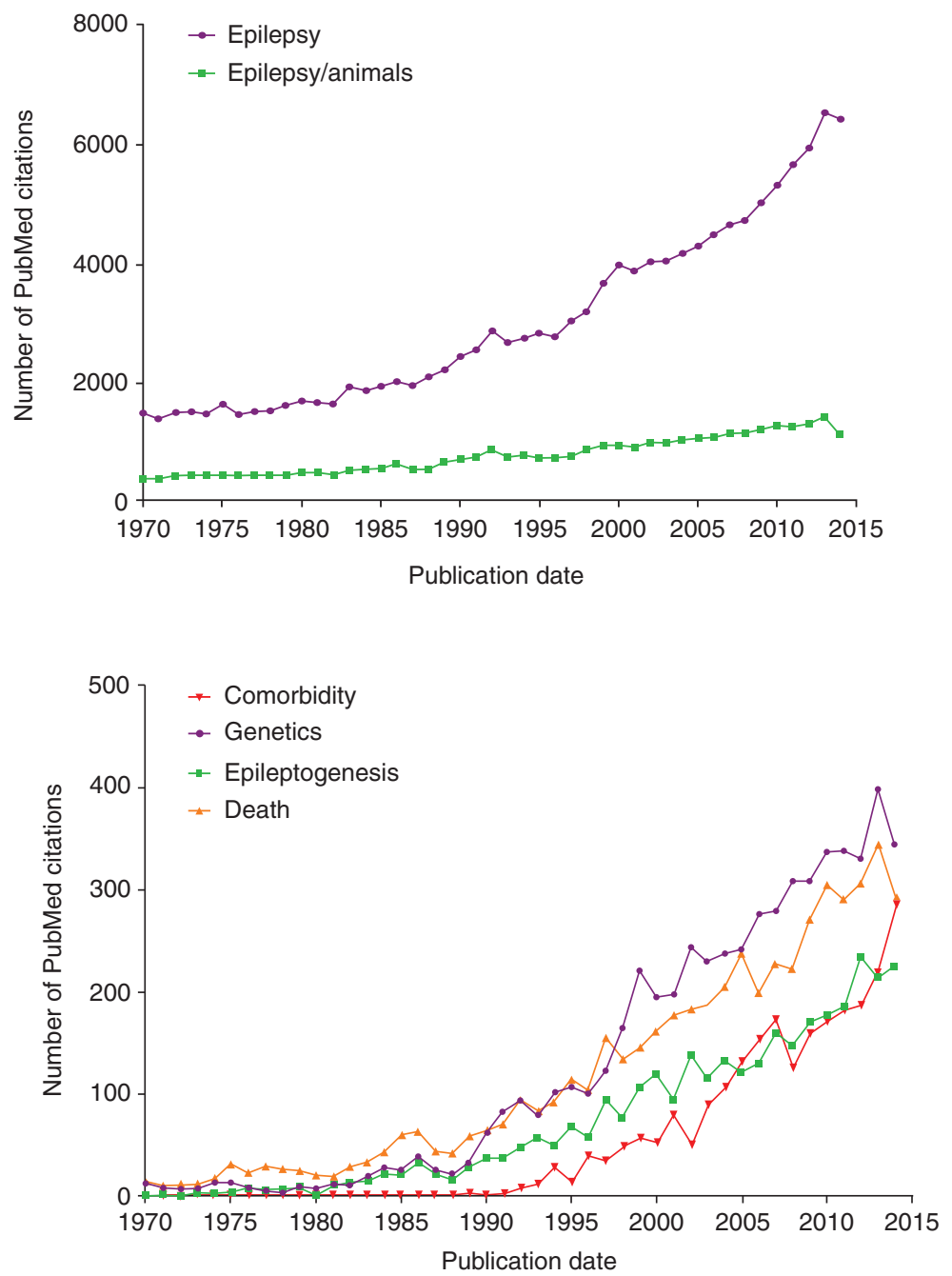

Figure 1. Number of PubMed citations for "epilepsy" and "epilepsy and animals" plotted at annual intervals (top) and for "epilepsy genetics," "epileptogenesis," "epilepsy and animals," and "epilepsy and death" (bottom).

different subtypes of seizure disorders and their comorbidities, which, once isolated, are proving highly tractable to experimental study.

In this article, we highlight a few important areas where there are many unanswered questions and where current research efforts are likely to have a large impact on patients living every day with epilepsy.

\section{THE EPILEPSY GENOME}

The list of single genes linked to epilepsy is expanding rapidly, promising to revolutionize the way we diagnose and treat hereditary seizure disorders (Ferraro 2012; Lee and Heo 2014; Martin et al. 2014; Myers and Mefford 2015). These monogenic disorders, numbering close to 150 by recent count, arise in families with a sufficiently informative pedigree that allows a highly penetrant mutation to be localized by conventional mapping and sequencing techniques. Increasingly, they are also discovered as sporadic de novo mutations when assessed in parental/proband trios, and indeed this pattern offers the simplest means of discovering novel candidate genes, whether by whole 
Targeting Future Research Challenges

exome or whole genome sequencing complemented by copy number variant analysis. Although de novo gene variants in an individual with epilepsy born from unaffected parents are rarely found in isolation, the rather small number of such variants permits a reasonably efficient bioinformatic process to filter for frequency, evolutionary conservation, and predicted functional severity of the gene disruption. Although identifying the identical variant in multiple probands with similar patterns of epilepsy is reassuring, additional anatomical and functional assessment of the gene and variant is required to advance it to candidate mutation status. Final validation typically requires expression of the variant in a model system that confirms its role in the expression of an epilepsy phenotype. Many such genes have been identified using similar steps in spontaneous and engineered single-gene models in the mouse, and genetic heterogeneity is now a near-universal aspect of clinical epilepsy syndromes and seizure types (De Jonghe 2011;
Steinlein 2014). Many such genes have been identified using similar steps in spontaneous and engineered single-gene models in the mouse. Although these genes reveal the rich diversity of molecular pathways underlying epilepsy, a major and predictable fraction of them regulate the birth, development, and function of inhibitory interneurons (Fig. 2). This genetic convergence on synaptic inhibition validates much of what has been learned about the generation of seizures by experimentally disinhibiting cortical circuitry, and strongly overlaps with the proposed basis for many epilepsy comorbidities. Much remains to be learned from continued epilepsy gene discovery and comparisons with molecular pathways in cognition, depression, and autism.

The fraction of human epilepsy that is driven by mutations in a single gene is not yet known, but is small in relation to all individuals with epilepsy of unknown origin, most of whom are assumed to therefore have a polygenic basis for their seizures. This genetic complexity is

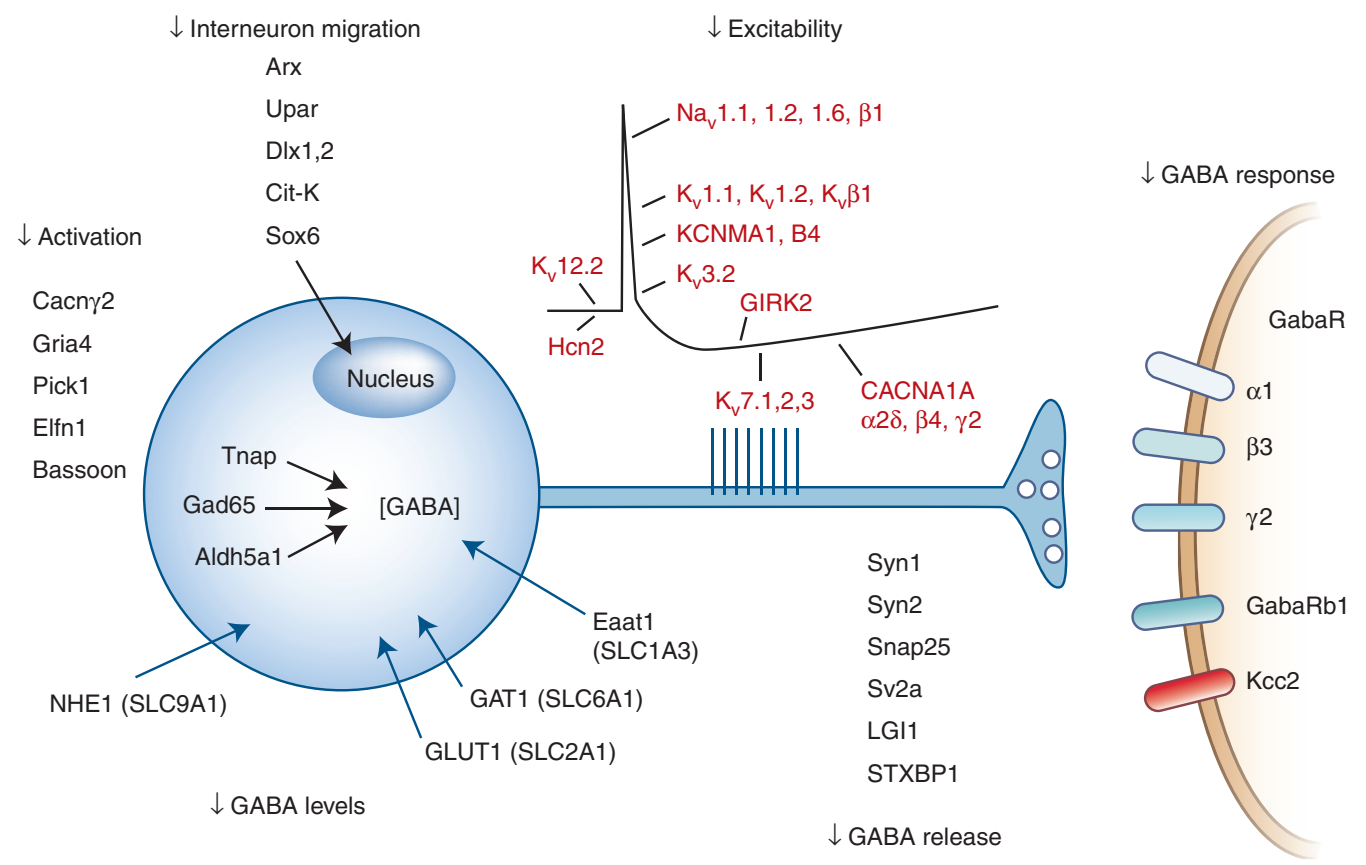

Figure 2. Biological convergence of genes linked to epilepsy phenotypes on the early migration, function, excitability, and synaptic transmission in $\gamma$-aminobutyric acid (GABA)ergic inhibitory interneurons. (From Noebels 2015; with permission, from the author.) 
consistent with the finding that many deleterious mutations, in particular those of voltage and ligand-gated ion channel genes, can be found in individuals without epilepsy (Klassen et al. 2011). The explanation for this lack of penetrance of ion channel mutations is readily apparent when one realizes that if present in the same brain network, a gain of function in one gene may mask the effect of a loss of function in another when they both contribute to excitability and transmitter release at cortical synapses. Thus, the specific pattern, rather than the absolute number of channel mutations in an individual is critical for determining seizure threshold. Epistasis, the modifying effects genes have on each other, has considerable significance for personalized genetic counseling, requiring that the full profile of variants present in an individual be considered before estimating the clinical impact of any single one. Developing a better biological understanding of multigenic complexity in variant profiles will be required to accurately interpret the potential severity and pharmacogenetic sensitivity of seizure disorders in the clinic.

What is currently not measurable without human tissue is the biological status of the genetically "at-risk" brain. Without this, the degree of penetrance in a single proband is unclear, and thus the predictive value of genomic variants remains obscure. Recent approaches to functionally validate epilepsy gene mutations in neurons derived from induced pluripotent stem cells (IPSCs) from the affected individual is an exciting strategy to overcome this gap in our ability to explain the pathophysiology of single genes on outbred genetic backgrounds (Liu et al. 2013). These studies may also ultimately help understand possible epigenetic changes at the posttranscritional level, which are not reflected in genomic analyses; however, such patterns could significantly differ among cell types in the brain. Unfortunately, fresh brain tissue from human epilepsy cases, even when available, are typically only available for study following years of pharmacotherapy and other seizure-induced damage, which engender potentially misleading molecular pathology.

\section{EPILEPTOGENESIS}

Epileptogenesis is the process by which a brain network that was previously normal is functionally altered toward increased seizure susceptibility, thus developing an enhanced probability to generate epileptic seizures (Pitkanen and Lukasiuk 2011; Sloviter and Bumanglag 2013). Epileptogenesis occurs following a variety of insults, such as traumatic brain injury, stroke, brain tumor, infections, neurodegeneration, and other insults of the brain. Genetic disorders, such as various ion channelopathies, neuronal migration disturbances, tuberous sclerosis complex, or Angelman syndrome, frequently develop epilepsy over time. In both categories, whether acquired or inherited, the critical hypothesis is that the insult triggers a wave of downstream molecular and structural change in the network leading to a destabilized network. Interruption of this reactive change should delay or prevent this excitability.

Although there have been numerous studies investigating the molecular, cellular, and network changes that occur following a brain insult, it remains poorly understood which of these changes result in spontaneous seizures, and which may be protective homeostatic responses. Figure 3 shows a schematic time line for brain changes occurring following a brain injury that can lead to epilepsy, and a partial listing of molecular and cellular events known to participate in epileptogenesis. In this case, status epilepticus (a prolonged seizure episode, generally defined as lasting at least one half hour) is portrayed as the precipitating factor for epileptogenesis. Both children and adults can develop chronic epilepsy after a single such episode of status epilepticus. For example, an otherwise normal child may have a prolonged febrile seizure or an adult may develop status epilepticus as a result of an infectious process. The status epilepticus is believed to signal the start of the epileptogenic process, eventually culminating in recurrent seizures and perhaps cognitive impairment. Determining the actual underlying etiological event for the episode of status epilepticus and which of these many changes can lead to the eventual development 
Targeting Future Research Challenges

\section{Seizures}
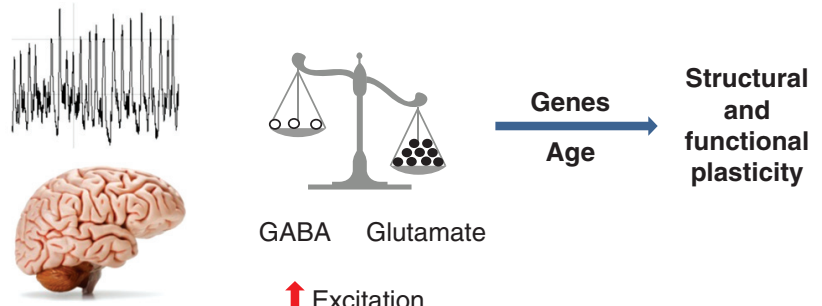

Network remodeling

GABA

Glutamate

Excitation

Inhibition

Internalization of GABA receptors

- Glutamate release

- In AMPA and NMDA receptors

- Oxidative stress

- Intracellular $\mathrm{Ca}^{2+}$

- Inflammation

Acute: seconds, minutes, hours

- Necrosis/apoptosis

- $\triangle$ GABA transmission

- Neurogenesis

axon sprouting

Semi-acute-chronic: hours, days

$\Delta$ in subunit composition of glutamate, AMPA, kainate, and GABA receptors Molecular/functional $\Delta$ in voltage-gated $\mathrm{Na}^{+}, \mathrm{Ca}^{2+}$-gated $\mathrm{K}^{+}, \mathrm{Ca}^{2+}$, and $\mathrm{HCN}$ - BDNF

Inflammation

$\Delta$ in signaling pathways involved in axon guidance, MAPK signaling, adhesion, TGF- $\beta$, ErbB, Wnt, and mTOR signaling, and regulation of actin skeleton

- Apoptosis

- Glutamate release

- Oxidative stress

- Intracellular $\mathrm{Ca}^{2+}$

- Inflammation

$\checkmark$ Neurogenesis

- BDNF

- Inflammation

- GABA currents in hippocampus/neocortex

- Excitation in the neocortex

- Impairment in spike frequency adaptation

- After-hyperpolarizing potentials

- Impaired long-term potentiation (LTP)

- Short-term plasticity

Chronic: days, weeks, months, years

Semi-acute-chronic: days, weeks, months

Seconds

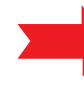

Minutes

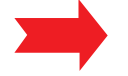

Days

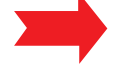

Weeks

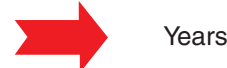

Figure 3. Schematic of status epilepticus (SE)-induced changes that occur over seconds to months. Similar changes can occur with spontaneous seizures (modified from Holmes 2015). GABA, $\gamma$-aminobutyric acid; AMPA, $\alpha$-amino-3-hydroxyl-5-methyl-4-isoxazolepropionate; NMDA, $N$-methyl-D-aspartate; BDNF, brainderived neurotrophic factor; HCN, hyperpolarization-activated cyclic nucleotide; TGF, transforming growth factor; mTOR, mechanistic target of rapamycin; MAPK, mitogen-activated protein kinases.

of seizures is challenging, and may differ by the status of brain maturation and chronological age. Because most individuals with brain insults, such as status epilepticus or head trauma, do not develop epilepsy, it is essential to identify biomarkers that will aid in identifying, predicting, and monitoring secondary epileptogenesis and disease progression, including biomarkers present very early after the injury/ insult that identify those people at risk for developing epilepsy (Gomes and Shinnar 2011; McClelland et al. 2011; Engel et al. 2013).
Such biomarkers could then be used to determine the individuals where intervention to prevent epilepsy is warranted, and even to follow the effects of treatment. Therefore, biomarker discovery is currently a high priority in epilepsy research.

Our understanding of the structural processes by which the brain recovers from injury is also quite limited. For example, axon sprouting commonly occurs following status epilepticus and other brain injuries resulting in epilepsy and has a strong correlation with epilepto- 
genesis, yet little is known regarding the synaptic strength and overall functional outcome of these complicated anatomical circuit alterations (Buckmaster 2014; Thom 2014). It is certainly not clear which injury-induced changes are contributing to epileptogenesis and which are compensatory. For example, increased neurogenesis with aberrant migration in the dentate gyrus following hippocampal status epilepticus is found in both animals and humans (Scharfman and Gray 2007; Scharfman and Hen 2007; Rakhade and Jensen 2009), yet it is unclear whether adding newborn cells to the existing population of granule cells is a beneficial means by which the brain compensates for seizure-induced apoptosis and necrosis, or is actually a contributing factor in epileptogenesis (Rotheneichner et al. 2013).

\section{EPILEPTOGENESIS AT THE TWO EXTREMES OF LIFE}

The greatest incidence of epilepsy occurs at the two extremes of life, in neonates and young children and in the older population (Annegers et al. 1995a,b; Hauser 1995). Remarkably little is known about differences in epileptogenic pathways in these vulnerable individuals, because the majority of animal model research is performed in young adulthood, the period when the onset of human epilepsy is least likely to appear. One cannot assume the mechanisms for epileptogenesis are the same across all ages, because there is now clear evidence that the immature brain, with developing neuronal circuits, responds quite differently than the mature brain with relatively fixed circuitry (Holmes et al. 2002b; Ben-Ari and Holmes 2008). Agerelated changes in inflammation, neurogenesis, sprouting, apoptosis/necrosis, and subunit changes of ionotropic and ligand-gated channels need to be specifically considered as investigators develop strategies to prevent epileptogenesis across all ages.

\section{EPILEPTIC ENCEPHALOPATHIES}

The epileptic encephalopathies describe a heterogeneous group of epilepsy syndromes associated with severe cognitive and behavioral dis- turbances (Shields 2000; Nabbout and Dulac, 2003; Berg et al. 2010). The key feature of the epileptic encephalopathies is that the slowing or regression of development is primarily the result of seizures, abnormal interictal cortical, and subcortical activity as reflected in the electroencephalogram (EEG), or both, and not the result of the underlying cause of the seizures (Nabbout and Dulac 2003). However, in some cases, it is clear that the gene causing the epileptic phenotype is also partially or totally responsible for the cognitive impairment (Bender et al. 2013). Indeed, in some single-gene models, there is evidence that a gain in cognitive function may coexist with epilepsy, suggesting that seizures are not always destructive and that the pathways for cognition and epilepsy can occasionally be dissected (Zhu et al. 2011).

The clinical and EEG features of the epileptic encephalopathies are varied and include such conditions as infantile epileptic encephalopathy with suppression burst (Ohtahara syndrome), early myoclonic encephalopathy, migrating partial epilepsy in infancy, infantile spasms (West syndrome), severe myoclonic epilepsy of infancy (Dravet syndrome), LennoxGastaut syndrome, myoclonic-astatic epilepsy, continuous spike-wave of sleep (CSWS), and Landau-Kleffner syndrome (Genton and Dravet 1997; Panayiotopoulos 2002; Nabbout and Dulac 2003).

The epileptic encephalopathies are also notoriously difficult to treat and, currently, most children with the disorders have medically intractable epilepsy and severe cognitive impairment. In relationship to the prevalence of epilepsy in general, the epileptic encephalopathies are rare syndromes. Yet, because of the age of onset and the severity of the condition, epileptic encephalopathies are a major health-care issue. Without a better understanding of the pathophysiology of epileptic encephalopathies, it is highly unlikely that novel therapies will be developed. Fortunately, the emergence of wholeexome sequencing (WES) of these cases is now identifying de novo causative mutations in a variety of genes, allowing the experimental development of informative mouse models and novel therapeutic targets. 
Targeting Future Research Challenges

\section{NEONATAL SEIZURES}

Children during the first months of life are at particularly high risk for seizures with the largest number of new-onset seizure disorders occurring during this time (Hauser 1995). There is considerable evidence that the immature brain is more susceptible to seizures than the mature brain (Ben-Ari and Holmes 2006). The propensity for seizures in the immature brain has been demonstrated in multiple experimental models (Holmes et al. 2002a). The enhanced excitability of the immature brain compared to the mature brain is related to the sequential development and expression of essential signaling pathways, along with the early patterns of synaptic connectivity that are refined with subsequent cortical maturation.

The development of $\gamma$-aminobutyric acid (GABA)ergic and glutamatergic synapses follows distinct timelines. During fetal development, GABAergic synapses develop before glutamatergic synapses (Khazipov et al. 2001). During the first few weeks of life, there is enhanced excitation because of an overabundance of $\mathrm{N}$-methyl-D-aspartate (NMDA) and $\alpha$-amino-3-hydroxyl-5methyl-4-isoxazole-propionate (AMPA) receptors (McDonald et al. 1990; Miller et al. 1990). With maturation, axonal collaterals and attendant synapses regress (Swann et al. 1991).

There are also developmental changes in the neurophysiology of the receptors (Stoneham et al. 2010). The NMDA excitatory postsynaptic currents (EPSCs) showed a maturational decrease in rise time but no change in decay time, whereas AMPA EPSCs show neither rise nor decay time changes with development. AMPA receptors possess mature kinetics and became the dominant glutamatergic current during early brain development. During the early postnatal period, at a time when the immature brain is highly susceptible to seizures, GABA, which in the adult brain is the primary inhibitory neurotransmitter, exerts a paradoxical depolarizing action (Ben-Ari et al. 2012). GABA is excitatory in early brain development because of a larger intracellular concentration of chloride found in immature neurons than in mature ones, because of maturational differenc- es between the two electroneutral chloride cotransporters KCC2 and NKCC1. The shift from a depolarizing to a hyperpolarizing chloride current occurs over an extended period depending on the age and developmental stage of the structure (Rheims et al. 2008). The depolarization by GABA of immature neurons is sufficient to generate $\mathrm{Na}^{+}$action potentials, to remove the voltage-dependent $\mathrm{Mg}^{2+}$ blockade of NMDA channels, and to activate voltage-dependent $\mathrm{Ca}^{2+}$ channels. These changes lead to a large influx of $\mathrm{Ca}^{2+}$ that, in turn, triggers long-term changes of synaptic efficacy. The synergistic action of GABA with NMDA and $\mathrm{Ca}^{2+}$ channels is unique to the developing brain and has many consequences on the impact of GABAergic synapses within the network.

The overabundance of synaptic connections, the increased intracellular $\mathrm{Cl}^{-}$resulting in a depolarizing effect of GABA, the overexpression of AMPA and NMDA receptors with a composition that enhances excitability of neuronal networks, and the lack of developed inhibitory networks all contribute to a high risk for seizures in the immature brain.

These developmental changes in neurotransmission have led to novel therapeutic approaches to neonatal seizures. To address whether the excitatory nature of GABA contribution to a greater seizure propensity and poor response to GABAergic anticonvulsants such as phenobarbital in newborns, bumetanide, a blocker of the NKCC1 transporter that prevents outward $\mathrm{Cl}^{-}$flux and causes a more negative GABA equilibrium potential $(\mathrm{E}[\mathrm{GABA}])$ in immature neurons has been studied in both in vivo and in vitro models of neonatal seizures (Dzhala et al. 2008; Mazarati et al. 2009). Unfortunately, the success of bumetanide in animal models has not yet been found to be effective or safe in newborns with seizures (Pressler et al. 2015). Age-specific therapies, taking into account the milieu of enhanced excitability in the immature brain, are urgently needed.

\section{EPILEPSY COMORBIDITIES}

Awareness of the molecular and cellular mechanisms responsible for seizures has resulted in a 
search for rational development of disease-specific therapy. However, compared to our knowledge of the pathophysiology of epilepsy, our understanding of the mechanisms responsible for its comorbidities lags far behind. Comorbidities, such as cognitive impairment, autism, and depression, may precede the onset of epilepsy, making it unlikely that seizures, in many cases, actually cause the comorbidities. However, there is a growing appreciation that, despite the lack of obvious causal relationships, there may be shared signaling pathways and network properties that are common to the epilepsy and the comorbidities. Given the enormous societal burden of these comorbidities, an important future challenge to investigators is to explore these commonalities and develop therapeutics that effectively target comorbid symptoms.

Of the comorbidities associated with epilepsy, cognitive abnormalities are the most common and severe (Holmes 1997, 2015). Mental retardation, learning disabilities, and memory impairment are increased in people with epilepsy. Individuals with pharmacoresistant epilepsy are at particular high risk for cognitive impairment, particularly when the seizures begin during early childhood (Berg et al. 2012). The consequences of such comorbidities greatly diminish the quality of life in individuals with epilepsy, and many people with epilepsy and their families consider the cognitive and behavioral consequences of seizures to be at least as troubling as the seizures themselves.

Although a wide range of neuropsychological deficits occur in individuals with epilepsy, memory disturbances comprise one of the other gravest problems (Bell et al. 2011). Understanding the mechanisms of such epilepsy-related memory impairment is the first step in developing therapeutic interventions. Although the human condition is clearly differs from that occurring in animals, human studies are often difficult to interpret because of the large number of variables associated with human epilepsy. Neuropsychological outcome in individuals with epilepsy may be influenced by multiple factors such as etiology, age of onset, duration of the disorder, seizure type, frequency, and severity, concomitant disorders, genetic background, and treatment history. Animal studies allow investigators control over most of these variables and have led to many fundamental insights into seizure-induced changes in the brain. The genetic, molecular, and physiological alterations associated with epilepsy have an important role on neuronal synchrony and neural rhythms, which play an important role in information processing and neuronal plasticity. It is not surprising that epilepsy, with a large population of neurons firing aberrantly, would have multiplicative consequences and propagate aberrant signals to connected structures. Although this abnormal signaling pattern stimulates epileptic activity, it also impedes normal information storage and retrieval in associated structures, with adverse cognitive consequences. There is a great need to know how propagation of epileptic discharges during seizures can perturb the networks in a way that results in cognitive impairment. It is fundamentally important to know whether strategies to protect cognition can be separated from strategies to reduce or eliminate seizures.

Network abnormalities common to both cognitive impairment and epilepsy may be amenable to modification via electrical or optogenetic stimulation techniques. Cranially implanted responsive neurostimulators that deliver stimulation to seizure foci via chronically implanted electrodes when specific electrocorticographic patterns are detected are already in use for patients with medically intractable epilepsy and a focal onset to their seizures (Bergey et al. 2015). Investigation into whether neurostimulation could improve cognitive dysfunction and possibly other comorbidities through control of oscillatory activity, although technically quite complex, is an essential future direction.

The most urgent comorbidity to study is the basis for sudden unexpected death in epilepsy (SUDEP), the leading cause of death from epilepsy. Each year, SUDEP occurs in 1 out of 1000 people with epilepsy, often in people between 20 and 40 years old, with a long history of tonicclonic seizures (Massey et al. 2014; Thurman et al. 2014). SUDEP refers to sudden deaths with no known postmortem explanation in in- 
Targeting Future Research Challenges

dividuals with epilepsy; the clinical observation is sudden cardiorespiratory collapse following a generalized seizure, and there are no current strategies for preventing it. Although it is likely the causes of SUDEP are multifactorial, genes have now been identified linking seizures, central autonomic dysfunction, cardiac arrhythmias, and sudden death. Mouse models bearing mutations in these genes are now revealing underlying mechanisms for cardiorespiratory shutdown following the seizure, including a fatal triggering of spreading depolarization in brainstem cardiorespiratory regulatory nuclei (Aiba and Noebels 2015). Determining how these genetic abnormalities can lead to spreading depolarization and SUDEP is critical to developing strategies that will predict and prevent SUDEP in high-risk individuals. Although genetic vulnerability may account for some cases of SUDEP, it is not yet known whether all SUDEP is the result of increased genetic risk. Future investigation into both structural and signaling dysfunction in brainstem pathways involved in forebrain control of respiration and the heartbeat are needed to better detect and prevent premature lethality in epilepsy.

\section{NOVEL THERAPEUTICS}

There is little compelling evidence that the ability of antiepileptic drugs (AEDs) to control seizures in individuals with epilepsy has improved dramatically since the introduction of carbamazepine in the 1970s. Although there have been advances in tolerability and safety with the introduction of modern AEDs, the new generation of drugs are similar to the older generation of drugs in overall efficacy against newonset epilepsy. In addition, there is no convincing evidence that current AEDs are reducing the proportion of patients with drug-resistant epilepsy. Given that individuals with epilepsy are often (although not invariably) extensively pharmacoresistant to several AEDs, each with different mechanisms of action, it is important to investigate other avenues to attack epilepsy.

As our understanding of the epilepsy genome matures, interesting and unexpected molecular targets have come into play. In the early discovery years, identification of the molecular target did not lead to major alterations in how epilepsy is treated. However, this is beginning to change. For example, the infantile epileptic encephalopathy caused by KCNQ2 mutation responds to retigabine/ezogabine, an AED that enhances voltage-gated $\mathrm{K}(\mathrm{V}) 7$ channels (Orhan et al. 2014). In a similar vein, migrating partial seizures of infancy is an early-onset epileptic encephalopathy syndrome that is typically resistant to treatment. The most common cause is a gain-of-function mutation in the potassium channel KCNT1. Quinidine, a partial antagonist of KCNT1 has been used to treat children with this encephalopathy (Bearden et al. 2014). Neonatal estradiol has been shown to have neuroprotective effects that alter the disease trajectory and prevent infantile spasms and seizures in the ARX model of catastrophic epilepsy (Olivetti et al. 2014). Greater effort in developing drugs that target the genetic mutation is likely to lead to more personalized treatments. Personalized medicine in epilepsy, where the person's genetic makeup can lead to prevention, screening, and treatment strategies, lags far behind cancer treatment, but has comparable potential to improve therapy.

Greater effort in developing drugs that target the genetic mutation is likely to lead to personalized medicine. Personalized medicine in epilepsy, where the person's genetic makeup can lead to prevention, screening, and treatment strategies, has lagged far behind cancer treatment, but has incredible potential.

Drug access to the brain is severely limited by a number of biological factors, particularly the blood-brain barrier (BBB), which impedes the ability of AEDs to enter and remain in the brain. More effective drug delivery to the epileptogenic brain tissue has the potential for improving seizure control. Therapies under development may result in the delivery of AEDs directly to the regions of the brain involved in seizures. In experiments with animal models of epilepsy, AEDs have been delivered successfully to seizure foci in the brain by programmed infusion pumps, acting in response to computerized EEG seizure detection (Stein et al. 2000; Stacey and Litt 2008). Inactive prodrugs can 
be given systemically and activated at the site of the seizure focus by locally released compounds, thus reducing systemic toxicity (Stein et al. 2000). A number of investigators are engineering nanoparticles, which can serve as a microdelivery system of drugs or be used to deliver antibodies or receptor-specific binding agents to selected brain regions (Bennewitz and Saltzman 2009). In the future, cell transplants that generate endogenous neurotransmitters and neuromodulators may have a role in epilepsy. Convection-enhanced delivery is a novel drugdelivery technique that uses positive hydrostatic pressure to deliver a fluid containing a therapeutic substance by bulk flow directly into the interstitial space within a localized region of the brain, circumventing the $\mathrm{BBB}$ and providing a wide and homogenous distribution of the drug (Rogawski 2009). Gene therapy may be useful in local drug delivery with the use of adenovirus, adenoassociated virus, herpesvirus, or other delivery vectors to induce brain cells to produce local modulatory substances (Boison 2007).

One of the biggest obstacles to drug delivery to the brain is the BBB (van Vliet et al. 2007, 2015). It is remarkable that $98 \%$ of small molecule and $100 \%$ of large drugs do not cross the BBB. Developing strategies to circumvent the $\mathrm{BBB}$ are urgently needed. One idea is that penetration of the BBB can be accomplished by linking large particles to iron transferrin or biological toxins that can cross the barrier. Additionally, overexpression of drug-resistant proteins, such as multidrug resistance gene 1 P-glycoprotein (MDR1) and multidrug resistance-associated protein 1 (MRP1) proteins lower the interstitial concentration of AEDs and thereby render the epilepsy caused by these pathologies resistant to treatment with AEDs (Aronica et al. 2012). Circumventing these proteins could lead to more effective treatment with currently available AEDs.

\section{SUMMARY}

There is little question that individuals living with epilepsy today are far better off than they were 30 years ago. Our ability to accurately diagnosis the disorder and provide safe and effective therapy has substantially improved. In some cases, epilepsy surgery can even result in a seizurefree period lasting many years. However, far too many individuals develop epilepsy as a result of genetic causes or acquired injury, and we have not succeeded in preventing the disorder. In addition, approximately a third of patients continue to have unremitting seizures despite optimal medical therapy. Comorbidities continue to be underrecognized, underappreciated, and are often inadequately treated because of a lack of knowledge about their neurobiological basis. Sudden unexpected death in epilepsy occurs far too often. Much more needs to be done for the sake of our patients and their families.

\section{REFERENCES}

Aiba I, Noebels JL. 2015. Spreading depolarization in the brainstem mediates sudden cardiorespiratory arrest in mouse SUDEP models. Sci Transl Med 7: $282 \mathrm{ra} 46$.

Annegers JF, Hauser WA, Lee JR, Rocca WA. 1995a. Incidence of acute symptomatic seizures in Rochester, Minnesota, 1935-1984. Epilepsia 36: 327-333.

Annegers JF, Hauser WA, Lee JR, Rocca WA. 1995b. Secular trends and birth cohort effects in unprovoked seizures: Rochester, Minnesota,1935-1984. Epilepsia 36: 575579.

Aronica E, Sisodiya SM, Gorter JA. 2012. Cerebral expression of drug transporters in epilepsy. Adv Drug Deliv Rev 64: 919-929.

Bearden D, Strong A, Ehnot J, DiGiovine M, Dlugos D, Goldberg EM. 2014. Targeted treatment of migrating partial seizures of infancy with quinidine. Ann Neurol 76: 457-461.

Bell B, Lin JJ, Seidenberg M, Hermann B. 2011. The neurobiology of cognitive disorders in temporal lobe epilepsy. Nat Rev Neurol 7: 154-164.

Ben-Ari Y, Holmes GL. 2006. Effects of seizures on developmental processes in the immature brain. Lancet Neurol 5: 1055-1063.

Ben-Ari Y, Holmes GL. 2008. Relevance of basic research to clinical data: Good answers, wrong questions! Epilepsy Curr 8: 19-22.

Ben-Ari Y, Khalilov I, Kahle KT, Cherubini E. 2012. The GABA excitatory/inhibitory shift in brain maturation and neurological disorders. Neuroscientist 18: 467486.

Bender AC, Natola H, Ndong C, Holmes GL, Scott RC, Lenck-Santini PP. 2013. Focal Scn1a knockdown induces cognitive impairment without seizures. Neurobiol Dis 54: 297-307.

Bennewitz MF, Saltzman WM. 2009. Nanotechnology for delivery of drugs to the brain for epilepsy. Neurotherapeutics 6: 323-336.

Berg AT, Berkovic SF, Brodie MJ, Buchhalter J, Cross JH, Van Emde BW, Engel J, French J, Glauser TA, Mathern GW, et 
al. 2010. Revised terminology and concepts for organization of seizures and epilepsies: Report of the ILAE Commission on Classification and Terminology, 20052009. Epilepsia 51: 676-685.

Berg AT, Zelko FA, Levy SR, Testa FM. 2012. Age at onset of epilepsy, pharmacoresistance, and cognitive outcomes: A prospective cohort study. Neurology 79: 1384-1391.

Bergey GK, et al. 2015. Long-term treatment with responsive brain stimulation in adults with refractory partial seizures. Neurology 84: 810-817.

Boison D. 2007. Cell and gene therapies for refractory epilepsy. Curr Neuropharmacol 5: 115-125.

Buckmaster PS. 2014. Does mossy fiber sprouting give rise to the epileptic state? Adv Exp Med Biol 813: 161-168.

De Jonghe P. 2011. Molecular genetics of Dravet syndrome. Dev Med Child Neurol 53: 7-10.

Dzhala VI, Brumback AC, Staley KJ. 2008. Bumetanide enhances phenobarbital efficacy in a neonatal seizure model. Ann Neurol 63:222-235.

Engel J Jr, Pitkanen A, Loeb JA, Dudek FE, Bertram EH III, Cole AJ, Moshe SL, Wiebe S, Jensen FE, Mody I, et al. 2013. Epilepsy biomarkers. Epilepsia 54: 61-69.

Ferraro TN. 2012. Discovery of epilepsy susceptibility genes: Implications for therapy development and pharmacogenomics. Pharmacogenomics 13: 731-734.

Genton P, Dravet C. 1997. Lennox-Gastaut and other childhood epileptic encephalopathies. In: Epilepsy: A comprehensive textbook (ed. Engel J Jr, Pedley TA), pp. 23552366. Lippincott-Raven, Philadelphia.

Gomes WA, Shinnar S. 2011. Prospects for imaging-related biomarkers of human epileptogenesis: A critical review. Biomark Med 5: 599-606.

Hauser WA. 1995. Epidemiology of epilepsy in children. Neurosurg Clin N Am 6: 419-429.

Holmes GL. 1997. Epilepsy in the developing brain: Lessons from the laboratory and clinic. Epilepsia 38: 12-30.

Holmes GL. 2015. Cognitive impairment in epilepsy: The role of network abnormalities. Epileptic Disord 17: $101-$ 116.

Holmes GL, Khazipov R, Ben-Ari Y. 2002a. New concepts in neonatal seizures. NeuroReport 13: A3-A8.

Holmes GL, Khazipov R, Ben-Ari Y. 2002b. Seizure-induced damage in the developing human: Relevance of experimental models. Prog Brain Res 135: 321-334.

Khazipov R, Esclapez M, Caillard O, Bernard C, Khalilov I, Tyzio R, Hirsch J, Dzhala V, Berger B, Ben-Ari Y. 2001 Early development of neuronal activity in the primate hippocampus in utero. J Neurosci 21: 9770-9781.

Klassen T, Davis C, Goldman A, Burgess D, Chen T, Wheeler D, McPherson J, Bourquin T, Lewis L, Villasana D, et al. 2011. Exome sequencing of ion channel genes reveals complex profiles confounding personal risk assessment in epilepsy. Cell 145: 1036-1048.

Lee BI, Heo K. 2014. Epilepsy: New genes, new technologies, new insights. Lancet Neurol 13: 7-9.

Liu Y, Lopez-Santiago LF, Yuan Y, Jones JM, Zhang H, O’Malley HA, Patino GA, O’Brien JE, Rusconi R, Gupta A, et al. 2013. Dravet syndrome patient-derived neurons suggest a novel epilepsy mechanism. Ann Neurol 74: $128-139$.
Martin HC, Kim GE, Pagnamenta AT, Murakami Y, Carvill GL, Meyer E, Copley RR, Rimmer A, Barcia G, Fleming $\mathrm{MR}$, et al. 2014. Clinical whole-genome sequencing in severe early-onset epilepsy reveals new genes and improves molecular diagnosis. Hum Mol Genet 23: 3200-3211.

Massey CA, Sowers LP, Dlouhy BJ, Richerson GB. 2014. Mechanisms of sudden unexpected death in epilepsy: The pathway to prevention. Nat Rev Neurol 10: 271-282.

Mazarati A, Shin D, Sankar R. 2009. Bumetanide inhibits rapid kindling in neonatal rats. Epilepsia 50: 2117-2122.

McClelland S, Dube CM, Yang J, Baram TZ. 2011. Epileptogenesis after prolonged febrile seizures: Mechanisms, biomarkers and therapeutic opportunities. Neurosci Lett 497: 155-162.

McDonald JW, Johnston MV, Young AB. 1990. Differential ontogenic development of three receptors comprising the NMDA receptor/channel complex in the rat hippocampus. Exp Neurol 110: 237-247.

Miller LP, Johnson AE, Gelhard RE, Insel TR. 1990. The ontogeny of excitatory amino acid receptors in the rat forebrain. II: Kainic acid receptors. Neuroscience 35: $45-51$.

Myers CT, Mefford HC. 2015. Advancing epilepsy genetics in the genomic era. Genome Med 7: 91.

Nabbout R, Dulac O. 2003. Epileptic encephalopathies: A brief overview. J Clin Neurophysiol 20: 393-397.

Noebels J. 2015. Pathway-driven discovery of epilepsy genes. Nat Neurosci 18: 344-350.

Olivetti PR, Maheshwari A, Noebels JL. 2014. Neonatal estradiol stimulation prevents epilepsy in Arx model of Xlinked infantile spasms syndrome. Sci Transl Med 6: 220ra12.

Orhan G, Bock M, Schepers D, Ilina EI, Reichel SN, Loffler H, Jezutkovic N, Weckhuysen S, Mandelstam S, Suls A, et al. 2014. Dominant-negative effects of KCNQ2 mutations are associated with epileptic encephalopathy. Ann Neurol 75:382-394.

Panayiotopoulos CP. 2002. Epileptic encephalopathies in early childhood. In: A clinical guide to epileptic syndromes and their treatment (ed. Panayiotopolous CP), pp. $70-$ 88. Bladon Medical, Oxfordshire, UK.

Pitkanen A, Lukasiuk K. 2011. Mechanisms of epileptogenesis and potential treatment targets. Lancet Neurol 10: 173-186.

Pressler RM, Boylan GB, Marlow N, Blennow M, Chiron C, Cross JH, De Vries LS, Hallberg B, Hellstrom-Westas L, Jullien V, et al. 2015. Bumetanide for the treatment of seizures in newborn babies with hypoxic ischaemic encephalopathy (NEMO): An open-label, dose finding, and feasibility phase 1/2 trial. Lancet Neurol 14: 469-477.

Rakhade SN, Jensen FE. 2009. Epileptogenesis in the immature brain: Emerging mechanisms. Nat Rev Neurol 5: 380-391.

Rheims S, Minlebaev M, Ivanov A, Represa A, Khazipov R, Holmes GL, Ben-Ari Y, Zilberter Y. 2008. Excitatory GABA in rodent developing neocortex in vitro. J Neurophysiol.

Rogawski MA. 2009. Convection-enhanced delivery in the treatment of epilepsy. Neurotherapeutics 6: 344-351. 


\section{G.L. Holmes and J.L. Noebels}

Rotheneichner P, Marschallinger J, Couillard-Despres S, Aigner L. 2013. Neurogenesis and neuronal regeneration in status epilepticus. Epilepsia 54: 40-42.

Scharfman HE, Gray WP. 2007. Relevance of seizure-induced neurogenesis in animal models of epilepsy to the etiology of temporal lobe epilepsy. Epilepsia 48: 33-41.

Scharfman HE, Hen R. 2007. Neuroscience. Is more neurogenesis always better? Science 315: 336-338.

Shields WD. 2000. Catastrophic epilepsy in childhood. Epilepsia 41: S2-S6.

Sloviter RS, Bumanglag AV. 2013. Defining "epileptogenesis" and identifying "antiepileptogenic targets" in animal models of acquired temporal lobe epilepsy is not as simple as it might seem. Neuropharmacology 69: 3-15.

Stacey WC, Litt B. 2008. Technology insight: Neuroengineering and epilepsy-designing devices for seizure control. Nat Clin Pract Neurol 4: 190-201.

Stein AG, Eder HG, Blum DE, Drachev A, Fisher RS. 2000 An automated drug delivery system for focal epilepsy. Epilepsy Res 39: 103-114.

Steinlein OK. 2014. Genetic heterogeneity in familial nocturnal frontal lobe epilepsy. Prog Brain Res 213: 1-15.

Stoneham ET, Sanders EM, Sanyal M, Dumas TC. 2010 Rules of engagement: Factors that regulate activity-de- pendent synaptic plasticity during neural network development. Biol Bull 219: 81-99.

Swann JW, Smith KL, Brady RJ. 1991. Age-dependent alterations in the operations of hippocampal neural networks. Ann NY Acad Sci 627: 264-276.

Thom M. 2014. Review: Hippocampal sclerosis in epilepsy: A neuropathology review. Neuropathol Appl Neurobiol 40: $520-543$.

Thurman DJ, Hesdorffer DC, French JA. 2014. Sudden unexpected death in epilepsy: Assessing the public health burden. Epilepsia 55: 1479-1485.

van Vliet EA, da Costa AS, Redeker S, van SR, Aronica E, Gorter JA. 2007. Blood-brain barrier leakage may lead to progression of temporal lobe epilepsy. Brain 130: 521534.

van Vliet EA, Aronica E, Gorter JA. 2015. Blood-brain barrier dysfunction, seizures and epilepsy. Semin Cell Dev Biol 38: 26-34.

Zhu PJ, Huang W, Kalikulov D, Yoo JW, Placzek AN, Stoica L, Zhou H, Bell JC, Friedlander MJ, Krnjevic K, et al. 2011. Suppression of PKR promotes network excitability and enhanced cognition by interferon- $\gamma$-mediated disinhibition. Cell 147: 1384-1396. 


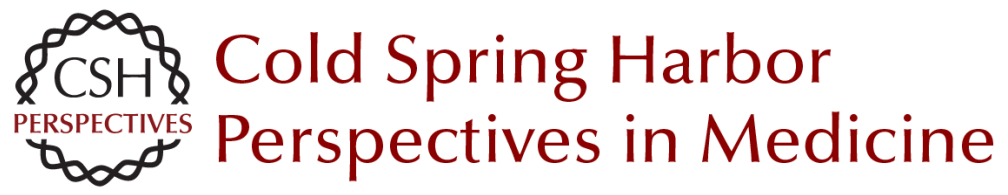

\section{The Epilepsy Spectrum: Targeting Future Research Challenges}

Gregory L. Holmes and Jeffrey L. Noebels

Cold Spring Harb Perspect Med 2016; doi: 10.1101/cshperspect.a028043

Subject Collection Epilepsy: The Biology of a Spectrum Disorder

The Epilepsy Spectrum: Targeting Future Research Challenges

Gregory L. Holmes and Jeffrey L. Noebels

Role of Sodium Channels in Epilepsy

David I. Kaplan, Lori L. Isom and Steven Petrou

\section{Mechanisms of Action of Antiseizure Drugs and the Ketogenic Diet Michael A. Rogawski, Wolfgang Löscher and Jong M. Rho}

Epilepsy and Autism

Ashura W. Buckley and Gregory L. Holmes

Immunity and Inflammation in Epilepsy Annamaria Vezzani, Bethan Lang and Eleonora Aronica

Hyperpolarization-Activated Cyclic Nucleotide-Gated (HCN) Channels in Epilepsy Gary P. Brennan, Tallie Z. Baram and Nicholas P. Poolos

The Role of Calcium Channels in Epilepsy Sanjeev Rajakulendran and Michael G. Hanna Interneuron Transplantation as a Treatment for Epilepsy

Robert F. Hunt and Scott C. Baraban

\section{Common Mechanisms Underlying \\ Epileptogenesis and the Comorbidities of Epilepsy \\ Andrey Mazarati and Raman Sankar}

The Diathesis-Epilepsy Model: How Past Events Impact the Development of Epilepsy and Comorbidities

Christophe Bernard

Potassium Channels in Epilepsy

Rüdiger Köhling and Jakob Wolfart

\section{GABAergic Synchronization in Epilepsy Roustem Khazipov \\ Status Epilepticus \\ Syndi Seinfeld, Howard P. Goodkin and Shlomo Shinnar}

Neonatal and Infantile Epilepsy: Acquired and Genetic Models Aristea S. Galanopoulou and Solomon L. Moshé

Epigenetics and Epilepsy

David C. Henshall and Katja Kobow

Microcircuits in Epilepsy: Heterogeneity and Hub

Cells in Network Synchronization Anh Bui, Hannah K. Kim, Mattia Maroso, et al.

For additional articles in this collection, see http://perspectivesinmedicine.cshlp.org/cgi/collection/ 